\title{
Assessing the Possibility of Leadership Education as Psychosocial- Based Problem Behavior Prevention for Adolescents: A Review of the Literature
}

\author{
Theodore L. Caputi \\ Joseph Wharton Scholar \\ The Wharton School \\ University of Pennsylvania \\ Junior Fellow, Drug Policy Institute \\ Division of Addiction Medicine \\ Department of Psychiatry \\ University of Florida
}

\begin{abstract}
The purpose of this review is to examine theoretical connections between adolescent leadership education and problem behavior prevention. Both the problem behavior prevention literature and the leadership education literature were reviewed for studies pertaining to the development of psychosocial traits. In the leadership education literature this research focused on the development of leadership potential, as this was considered most closely linked with leadership education for adolescents as opposed to leadership education focused on honing skills in established leaders. Because the purpose of this review was to determine if a theoretical connection exists between two previously unconnected fields of literature, a thorough literature review was conducted as opposed to a systematic review because it was deemed too cumbersome. Instead, salient studies from both fields were examined for their applicability to the other field and the analysis as a whole. The research found significant overlap in psychosocial protective factors for problem behaviors and the psychosocial traits developed through leadership education. This paper includes a review and synthesis of the two literatures, as well as direct comparisons between them. Given that a theoretical connection between leadership education and problem behavior prevention seems to exist, the author recommends empirical research to determine if leadership education is an effective and efficient vehicle for problem behavior prevention. The paper will conclude with recommendations for leadership education practitioners, as well as other key stakeholders.
\end{abstract}

\section{Introduction}

Antisocial or problem behaviors, such as alcohol use, drug use, and precocious and risky sex, continue to be a problem among adolescents in the United States. Risk behaviors (also known as problem behaviors) can impair an adolescent's development, as well as cause harm to his or her health (Jessor, 1991). Therefore, to promote the goal of long-term health and wellbeing among American youth, American organizations, communities, and schools must consider effective methods to prevent risk behavior among adolescents. The purpose of this review is to determine if a theoretical framework exists that can connect leadership education with problem behavior prevention among adolescents. 
Background. Hawkins, Catalano, and Miller (1992) was among the first to examine the etiology of high-risk behavior in the context of risk factors (Brook, Brook, Gordon, Whiteman, \& Cohen, 1990; Garmezy, 1985; Rutter, 1985). Hawkins et al. synthesized the results of several studies that focused on the relationships between social, personal, and biological variables and drug abuse to identify 17 specific risk factors for drug abuse and determined that the absence of any one of the risk factor could be considered a preventative factor. This work led to the development of Social Development Theory, which finds that four processes condition children towards either pro-social or antisocial (delinquent) activity: perceived opportunities for involvement in activities and interactions with others, the degree of involvement and interaction, the skills to participate in these involvements and interaction, and the reinforcement they perceive as forthcoming from performance in activities and interactions (Catalano \& Hawkins, 1996, p. 55). For a full review of the theory, see Catalano \& Hawkins (1996). Social development theory, and specifically the identification of risk and protective factors, had a dramatic effect on risk behavior prevention, as youth organizations and policy groups took on risk-factor-based prevention methods, not only for drug abuse prevention, but for risk behavior prevention in general (e.g., Tebes et al., 2007; Botvin, Baker, Dusenbury, Botvin, \& Diaz, 1995; Ellickson, McCaffrey, Ghosh-Dastidar, \& Longshore, 2003; Hawkins \& Catalano, 1992).

Over the past two decades the 17 risk factors identified by Hawkins et al. (1991) have been further refined, developed, and validated (e.g., Dugan, 1996; Terzian, Andrews, \& Moore, 2011). These risk behaviors have been addressed by numerous prevention programs conducted by schools, youth organizations, and community groups.

One possible method to build protective factors and mitigate risk factors among adolescents is youth leadership education. Participation in leadership activities enable young people to interact positively with adults and other community members, be highly engaged in pro-social activities, and receive positive reinforcement for positive accomplishments; therefore, it stands to reason that, in the framework of social development theory, leadership education may be a vehicle to promote pro-social behavior in adolescents. Findings in the literature suggest that leadership education addresses environmental, personal, and behavioral traits similar to problem behavior protective factors for antisocial behavior, and so logically, leadership education seems worthy of future research for its potential in preventing adolescent antisocial behavior. This review will provide recommendations for researchers, leadership educators, prevention policy makers, as well as concerned parents looking for childrearing strategies that prevent delinquent behavior.

Methodology. This study is predicated on the research performed by Jessor (1991) which validated Problem Behavior Syndrome, and by Hawkins et al. (1992), which established the psychosocial trait-based approach to problem behavior prevention. Risk factors for substance abuse identified by Hawkins et al. can be extrapolated to other problem behaviors, in accordance with Jessor's (1991) Problem Behavior Theory. Therefore, we can apply findings about a connection between leadership education and substance abuse risk factors to other problem behaviors, including violence, and precocious and risky sex. 
First, literature related to leadership education, particularly leadership education intended for adolescents, was reviewed to get a sense for how leadership education researchers understand the effect of leadership education on psychosocial traits. The publications and databases reviewed include: Journal of Leadership Education, Journal of Agricultural Education, International Journal of Teaching and Learning in Higher Education, American Psychologist (published by the American Psychological Association), Journal of Park and Recreation Administration, Human Resource Management, School Leadership and Management, Personnel Review, Leadership Quarterly, ERIC (Educational Resource Information Center) and EBSCOHost.

Next, the available literature related to the field of adolescent problem behaviors was reviewed. Reviewed publications and databases include: PsycInfo, Pubmed, ChildTrends, Journal of Adolescent Health, Cognitive Therapy and Research, Psychological Bulletin, and Journal of Adolescent Health. For those less familiar with problem behavior research, "risk behavior" must be distinguished from "risk-taking behavior" (Jessor, 1991). Risk-taking behavior indicates deliberate thrill seeking (e.g., going bungee-jumping to see if one can survive it). Risk behavior, on the other hand, is inherently risky, but does not indicate deliberately thrill seeking; as stated by Jessor (1991) "few adolescents continue cigarette smoking [a risk behavior] for the thrill of seeing whether they can avoid pulmonary disease" (p. 599). In this search, I define adolescence as the period of psychological adjustment made in preparation for adulthood (Peterson \& Epstein, 1991). Although adolescence commonly coincides with puberty, the processes are separate, and according to Peterson and Epstein, the biological process of puberty has little consequence on the psychological process of adolescence.

The author synthesized and compared literature from both fields to determine whether a connection exists between the psychosocial traits enhanced by leadership education and those that are preventative factors against problem behaviors among adolescents. Finally, the author used the synthesis and comparison to formulate recommendations for researchers, educators, and parents.

The author notes that the greatest potential for error in this review is due to the different terminologies used to describe psychosocial traits in the leadership education and problem behavior prevention fields. While the specific terms used differed between the two fields, the meanings of the terms were often similar. However, bridging the terminology from both fields leaves room for misunderstanding or ambiguity. For instance, Popper and Mayseless (2007) described "care for others" (p. 5) as a personality trait enhanced by leadership education, and Jessor (1987) described a "high value on affection" (p. 333) to be a preventative factor against problem behaviors. These two traits, care for others and high value on affection, are generally the same, but may vary in nuance.

\section{Defining and Measuring Leadership Potential Among Adolescents}

Although leadership education has become more prevalent among youths over the past few decades (Murphy \& Reichard, 2012), the majority of the leadership education literature available describes techniques intended for adults. Therefore, like other papers in the field (e.g., Murphy, 2011), this literature review will begin with the broader context of adult leadership 
education and then attempt to make connections to opportunities for leadership development in adolescents.

What is Leadership Potential for Adults? Because leadership education for adolescents focuses on making leaders out of individuals with minimal or no previous leadership experience, the study of leadership potential is of particular concern to this review. Fortunately, leadership potential in adults is well researched because it has value to corporations and organizations preparing their up-and-coming leaders (e.g., Hogan, Curphy, \& Hogan, 1994; Dries \& Pepermans, 2012).

To discuss "leadership potential," it must first be distinguished from success within a non-leadership role (Dries \& Pepermans, 2007). Leadership potential is a measure of the predicted future success of a leader. Prior success in a non-leadership role, on the other hand, does not predict ability within a leadership position. Even in the case of adult corporate workers, it is important to separate an individual's skills indicating leadership potential from his or her proficiency in performing his or her current job.

Leadership potential in adults has been defined in several different ways. For instance, Spreitzer, McCall, and Mahoney (1997) identified leadership potential as the combination of end-state competencies and learning-oriented competencies, indicating what one knows and what one is willing to learn, respectively. This definition lends itself to leadership in a particular field, in which specific competencies are important. More frequently, leadership researchers have stated that leadership potential is independent of field and best measured by psychosocial traits (e.g., Reichard, Riggio, Guerin, Oliver, Gottfried, \& Gottfried, 2011). These personality traits can be mapped in several ways (e.g., Dries \& Pepermans, 2012), but most studies have similar findings. In the interest of a common understanding among psychosocial analysts, this review will consider personality on the standard, "big-five" personality model, which measures the most salient domains of personality: extraversion, agreeableness, conscientiousness, neuroticism, and intellect. A study by Hogan, Curphy, and Hogan (1994) found that extraversion, agreeableness, and neuroticism are significantly related with being perceived as "leader-like" among adults. This conclusion has been verified by other models, which measured leadership potential based on similar traits (Dries \& Pepermans, 2012). Therefore, leadership potential can be fostered by developing these three fields of personality traits.

What is Leadership Potential for Adolescents? Far more research has been conducted to analyze, evaluate, and measure leadership potential in adults than in adolescents. Fortunately, leadership psychology researchers have found strong similarities in the development of leadership potential in adults and leadership education for adolescents (Schneider, Ehrhart, \& Ehrhart, 2002), and so certain inferences about adolescent leadership can be made from research centered on adults.

For example, like for adults, leadership potential in adolescents can also be measured through psychosocial traits (Schneider, Paul, White, \& Holcombe, 2000). Further, the personality traits most related to leadership potential are the same for adolescents as for adults: extraversion, agreeableness, and neuroticism. Comparing individual traits for leadership potential is difficult because different researchers use different terms and levels of specificity to describe the same 
basic traits. The goal of this sample is to highlight personality traits associated with leadership potential that are also of importance to the psychosocial approach to risk behavior prevention. This sample is not intended to include all personality traits that are important to leadership potential. This review will use a sample of traits synthesized from a non-exhaustive review of studies.

- Self-confidence, including:

$\circ$ Low trait anxiety

- General self-efficacy

- Internal locus of control (Popper \& Mayseless, 2007)

- Care for others (Popper \& Mayseless, 2007)

- Pro-active, optimistic orientation (Popper \& Mayseless, 2007)

- Openness (Popper \& Mayseless, 2007)

- Dominance (Schneider et al., 2000; Schneider et al., 2002)

- Independence (Schneider et al., 2000; Schneider et al., 2002)

In addition, Dries and Pepermans (2012) and McCormick, Tanguma, and Lopez-Forment (2002) found that the following traits were related to leadership potential in adults. It can be assumed that these same traits would be related to leadership potential in adolescents, as well:

- Ability to turn information into action (Dries \& Pepermans, 2012)

- Willingness and ability to learn from experience (Dries \& Pepermans, 2012)

- Willingness to make the sacrifices of a leader (Dries \& Pepermans, 2012)

- Attraction or orientation towards leadership (Dries \& Pepermans, 2012)

- Self-efficacy in leadership (McCormick et al., 2002)

- Motivation (McCormick et al., 2002)

- Persistence (McCormick et al., 2002)

- Goal-directedness (McCormick et al., 2002)

- Resilience (McCormick et al., 2002)

Similar to adults, there are some discrepancies about evaluating leadership potential among adolescents. Because the aforementioned list is a compilation of traits researched in a variety of studies, no single measurement tool has been used to evaluate all of the traits. Out of the studies reviewed, however, Schneider et al. (2000) used the most comprehensive collection of measurement tools to evaluate leadership potential in adolescents. Schneider et al. measured a sample of 242 high school students on the criteria of personality, interests, motivation, behavior, and skills/ability (including intellectual ability). Measurement tools used by Schneieder et al. are described in Table 1. 
Table 1: Criteria and Measurement Tools for Schneider et al. (2000)

\begin{tabular}{|c|c|c|}
\hline Criteria & $\begin{array}{l}\text { Measurement } \\
\text { Tool }\end{array}$ & Explanation \\
\hline Personality & $\begin{array}{l}\text { Myers-Briggs } \\
\text { Type Indicator }\end{array}$ & $\begin{array}{l}\text { Survey that considers four continuous variables: } \\
\text { extraversion, sensing, thinking, and judging }\end{array}$ \\
\hline Interests & $\begin{array}{l}\text { Campbell Interest } \\
\text { Skills Survey }\end{array}$ & $\begin{array}{l}\text { Self-rated skills and interests report that evaluates seven } \\
\text { "orientations": influencing, organizing, helping, creating, } \\
\text { analyzing, producing, and adventuring }\end{array}$ \\
\hline Motivation & $\begin{array}{l}\text { Miner Sentence } \\
\text { Completion Scale }\end{array}$ & $\begin{array}{l}\text { Survey collects written responses that were assigned point } \\
\text { values indicating motivation to lead. Note: MSCS failed in } \\
\text { predicting leadership behavior, perhaps because the } \\
\text { students found the measure (which was created in 1961) to } \\
\text { be out of date and sexist. }\end{array}$ \\
\hline Behavior & $\begin{array}{l}\text { Leaderless Group } \\
\text { Discussion }\end{array}$ & $\begin{array}{l}\text { Students were assigned randomly to groups of four or five } \\
\text { and then evaluated on socio-emotional and task-oriented } \\
\text { leadership behaviors when asked to develop hypothetical } \\
\text { plans for crisis situations }\end{array}$ \\
\hline \multirow[t]{2}{*}{ Skills/Ability } & $\begin{array}{l}\text { Campbell Interest } \\
\text { Skills Survey }\end{array}$ & See Interests \\
\hline & $\begin{array}{l}\text { Grade Point } \\
\text { Average }\end{array}$ & $\begin{array}{l}\text { SAT and PSAT scores were not available for all students, } \\
\text { but analysis on a subsample of } 42 \text { students found a strong } \\
\text { positive relationship between GPA and PSAT scores as } \\
\text { well as between GPA and SAT scores, indicating that } \\
\text { GPA was a fair measure of intelligence. }\end{array}$ \\
\hline
\end{tabular}

Development of a measure for adolescent leadership potential is beyond the scope of this review, but the tools used by Schneider et al. (2000), excluding the Miner Sentence Completion Scale, seem reasonably effective. It is suggested that leadership potential also include positive perceptions of youth/adolescent role in leadership capacities. Because adolescents rarely have high-powered leadership positions, it is important to measure their view of leadership opportunities (Jones, 2009).

\section{Leadership Education Among Adolescents}

The goal of leadership education among adolescents is to improve the leadership potential of the adolescents. This section will review the proven effectiveness of leadership education and the outcomes on which leadership education programs should focus in order to be effective.

Is Leadership Education Among Adolescents Measurably Effective? Nationally, a wide variety of leadership education programs have been instituted for adolescent students throughout the country. Similar to synthesizing a list of personality traits related to leadership potential, this research was difficult because different programs focused on different outcomes. An exhaustive list of successful leadership development models and programs is beyond the 
scope of this review, but this review will highlight a few programs successful in developing the personality traits relevant to risk-behavior prevention (see the section, "Problem Behavior Prevention Among Adolescents").

Swigert and Boyd (2010) studied the effects of participation in the Keystone Club, an arm of the Boys \& Girls Club of America focused on leadership and character development, on its student alumni. The researchers interviewed 14 alumni and found that the program increased the students' patience, integrity, confidence, altruism, encouragement, motivation, and persistence. Higham, Freathy, and Wegerif (2010) extensively interviewed five out of sixty 1318-year-old students who attended a 2-day leadership education program. The researchers found increases in confidence and openness. The study concluded "students can demonstrate responsible leadership when given enough support in building the appropriate skills and habits for learning, and space for their dispositions for learning to develop" (Higham et al., 2010, p. 431). Stewart et al. (1985) studied the perceived effectiveness of the Future Farmers of America (FFA; now the National FFA Organization), an organization intended to develop leadership abilities within the agricultural youth community, among 431 members ( 212 current or past chapter officers, 219 current or past general members). While both members and officers reported achievement in character development, social development, interpersonal relations, and communication skills, officer ratings were consistently higher than those of general members. This finding suggests that a higher level of involvement in leadership training may increase the effectiveness of leadership development, which would prove the effectiveness of the FFA leadership development program. Research by Stewart et al., (1985) on the effectiveness of FFA leadership development was replicated more recently by the study performed on FFA members by Rutherford, Townsend, Briers, Cummins, and Conrad (2002). A study of the effectiveness of an all-girls leadership study also showed increases in expectation of self-efficacy and selfconfidence (Taylor \& Rosselli, 1997). A study by Marcketti and Kadolph (2010) showed with a study of 76 college students that brief leadership education interventions can change student beliefs regarding leadership and their own leadership efficacy. This finding suggests that if leadership education can change one's beliefs on leadership, it can also change one's leadership strategies and skills. Each of these aforementioned studies has proven that leadership development programs are capable of not only changing their participants' leadership ability, but also their participants' personal traits. The literature contains vast records of personal growth and improvement among adolescent students who partake in leadership development programs; for a more comprehensive review of successful adolescent leadership development programs, see Swigert and Boyd (2010).

\section{Problem Behavior Prevention Among Adolescents}

This review has identified certain traits indicated as a measure of leadership potential and verified that leadership education can enhance leadership potential and, thus, those traits. Now, this review will switch its attention to problem behavior prevention among adolescents. It will examine overlap between psychosocial traits that, if developed, have been identified as preventative factors for problem behavior. If many of the traits that are enhanced through leadership education are also considered preventative factors against problem behavior among adolescents, then leadership education may be a promising approach to prevent problem behavior among adolescents. 
Risk Factors for Prevention and the Problem Behavior Theory. For the past few decades, prominent psychological researchers have viewed problem behavior prevention through the lens of risk factors (e.g., Jessor, 1987, 1991; Donovan, 2004; Hawkins et al., 1992). Perhaps most familiar to problem behavior researchers is the seminal study performed by Hawkins and his colleagues (1992) which identified 17 personal, social, and biological risk factors for substance abuse. Obviously, some individual characteristics, such as genetic tendencies, could not be alleviated with leadership training, and so we will focus on personal (internal) risk factors.

Before the research performed by Hawkins et al. (1992) was published, however, Jessor (1987) had already developed the Problem Behavior Theory, which identified psychosocial risk factors that correlated to adolescent problem behavior, in general. As opposed to Hawkins et al. (1992), who had only studied substance abuse, Jessor's research (1987) suggests the broader concept of "Problem Behavior Syndrome," in which an adolescent who is at-risk for (or engages in) one problem behavior is also at-risk for many problem behaviors, including cannabis use, precocious sexual intercourse, drinking, problem drinking, and deviant behavior. This relatedness among problem behaviors makes the risk factors generalizable among problem behaviors. Therefore, this review will use Jessor's Problem Behavior Theory to explain the personality traits relevant to risk behavior prevention.

Problem-Behavior Theory (Jessor, 1987) examines an individual's personality, perceived environment, and behavior for certain variables that indicate "proneness," which is defined as the "likelihood of occurrence of normative transgression or problem behavior... behavior that departs from the norms" (p. 332). Jessor lists the following psychosocial variables as risk factors for problem behavior within the Personality System of the Problem Behavior Theory Framework:

- Low Value on Academic Achievement

- High Value on Independence

- Low Value on Affection

- Low Expectation for Academic Achievement (orientation toward a conventional institution - the school)

- Low Expectation for Independence (orientation toward autonomy and unconventionality)

- Low Expectation for Affection

- High Belief of Social Criticism

- High Belief of Alienation

- Low Self-esteem

- External locus of control

- Low Attitudinal Tolerance of Deviance

- Low Religiosity

Similar risk factors were identified by other studies (e.g., Flay, 2002; Donovan, 2004; Katz, Fromme, \& D'Amico, 2000). For instance, Donovan (2004) studied risk factors for alcohol initiation among adolescents, and found that lower values on academic achievement, lower expectations of academic achievement, and lower school motivation were all risk factors for alcohol initiation. Donovan (2004) also found that a lower orientation towards hard work and a high orientation towards rejection of parents were also correlated with alcohol initiation and could, therefore, be considered further risk factors. Katz, Fromme, and D'Amico (2000) also found that social conformity among adolescents was inversely related to positive expectancies 
for several risk behaviors, affirming the aforementioned risk factors. Although the aforementioned list of risk factors is non-comprehensive, it provides a workable sample of variables that are considered risk factors for problem behaviors among adolescents. Most psychosocial researchers (e.g., Jessor, 1987), believe that a preventative factor is just the negation or lack of a risk factor (i.e., having an external locus of control is a risk factor, not having an external locus of control is a preventative factor).

Jessor's Problem Behavior Theory (1987), which indicates a high correlation between many different adolescent risk behaviors (e.g., substance use, violence, risky sex, etc.), has been substantiated several times in the literature. Donovan's research (2004) affirms the Problem Behavior Theory in its finding that adolescents who were time- 1 abstainers and reported previous deviant behavior were more likely than their peers without previous deviant behavior to initiate alcohol use, suggesting relatedness between deviant or problem behaviors. Research performed by Katz, Fromme, and D'Amico (2000), which found that high correlations exist between different risk taking behaviors (e.g., substance use and risky sex), also affirmed the premise of the Problem Behavior Theory. Terzian et al. (2011) also suggests that risk behaviors often co-occur, and that in order for a program to be not only effective but also cost-effective, it should address common risk factors shared among several risk behaviors.

\section{What Kinds of Prevention Techniques Are Working to Address These Risk}

Factors? Interestingly, problem behavior prevention techniques that address the psychosocial health of adolescents have already been found effective. Flay (2000) reports that programs focusing on social skills are effective for prevention of substance use and unsafe sexual behaviors, character education, and mental health advancement. The study performed by Terzian et al. (2011) affirmed that programs focusing on social and emotional competencies (e.g., enhancing personality traits) were effective in preventing risky adolescent behaviors.

It seems as though researchers have a clear idea of what makes an effective problem behavior prevention program, and an analysis of the leadership education literature suggests that leadership education may fulfill the needs of an effective problem behavior prevention program.

\section{Results: Connection between Leadership Education and Problem Behavior Prevention}

This review has discussed how effective problem behavior prevention among adolescents should focus on psychosocial personality traits and that psychosocial personality traits, as measured in leadership potential, can be enhanced through leadership education. This suggests that, if the same psychosocial traits that are developed through leadership education are also the psychosocial traits associated with risk factors for adolescent risk behaviors, leadership education may be a promising (although untested) approach to problem behavior prevention. Analyzing the overlap between the set of psychosocial traits developed in leadership education and those associated with problem behavior prevention presented considerable difficulty in this review; the two literatures used different terminology to describe similar traits, and within each of the two sets of literature, different studies evaluated the same traits using different terminology. Just a review of the two sets of psychosocial traits in close proximity, however, reveals many similarities: 
Table 2: Comparison of Psychosocial Traits

\section{Psychosocial Traits Enhanced by} Leadership Education

- Self-confidence, including:

- Low trait anxiety

- General self-efficacy

- Internal locus of control (Popper \& Mayseless, 2007)

- Care for others (Popper \& Mayseless, 2007)

- Pro-active, optimistic orientation (Popper \& Mayseless, 2007)

- Openness (Popper \& Mayseless, 2007)

- Dominance (Schneider, Paul, White, \& Holcombe, 2000;

Schneider, Ehrhart, \& Ehrhart, 2002)

- Independence (Schneider et al., 2000, Schneider et al., 2002)

- Ability to turn information into action (Dries \& Pepermans, 2012)

- Willingness and ability to learn from experience (Dries \& Pepermans, 2012)

- Willingness to make the sacrifices of a leader (Dries \& Pepermans, 2012)

- Attraction or orientation towards leadership (Dries \& Pepermans, 2012)

- Self-efficacy in leadership (McCormick et al., 2002)

- Motivation (McCormick et al., 2002)

- Persistence (McCormick et al., 2002)

- Goal-directedness (McCormick et al., 2002)

- Resilience (McCormick et al., 2002)

\section{Psychosocial Traits Identified as Preventative Factors for Adolescent Problem Behavior}

- High Value on Academic Achievement

- Low Value on Independence

- High Value on Affection

- High Expectation for Academic Achievement (orientation toward a conventional institution - the school)

- High Expectation for Independence (orientation toward autonomy and unconventionality)

- High Expectation for Affection

- Low Belief of Social Criticism

- Low Belief of Alienation

- High Self-esteem

- Internal locus of control

- High Attitudinal Tolerance of Deviance

- High Religiosity (Jessor, 1987) 
For more accessible understanding, the following table highlights direct associations that can be made between the different terminologies used in the different literatures. The traits in each of the following rows can be associated with each other.

Table 3: Organized Comparison of Psychosocial Traits

\begin{tabular}{|c|c|c|}
\hline $\begin{array}{l}\text { Area of Big Five } \\
\text { Personality Model }\end{array}$ & $\begin{array}{l}\text { Psychosocial Traits Enhanced } \\
\text { by Leadership Education }\end{array}$ & $\begin{array}{c}\text { Psychosocial Traits Identified as } \\
\text { Preventative Factors for Adolescent } \\
\text { Problem Behavior } \\
\end{array}$ \\
\hline N/A & & High Religiosity \\
\hline Agreeableness & Care for others & $\begin{array}{l}\text { High value on affection; High } \\
\text { expectation for affection }\end{array}$ \\
\hline \multirow[t]{2}{*}{ Conscientiousness } & $\begin{array}{l}\text { Persistence; resilience; } \\
\text { willingness to make the } \\
\text { sacrifices of a leader }\end{array}$ & $\begin{array}{l}\text { High expectation for (academic) } \\
\text { achievement }\end{array}$ \\
\hline & Goal-directedness & High value on (academic) achievement \\
\hline \multirow[t]{3}{*}{ Extraversion } & $\begin{array}{l}\text { Pro-active, optimistic } \\
\text { orientation; motivation; } \\
\text { Attraction or orientation towards } \\
\text { leadership }\end{array}$ & $\begin{array}{l}\text { High expectation for Academic } \\
\text { Achievement }\end{array}$ \\
\hline & $\begin{array}{l}\text { Openness; willingness and } \\
\text { ability to learn from experience }\end{array}$ & High Attitudinal Tolerance of Deviance \\
\hline & $\begin{array}{l}\text { Ability to turn information into } \\
\text { action }\end{array}$ & \\
\hline \multirow[t]{4}{*}{ Neuroticism } & $\begin{array}{l}\text { Self-confidence: low trait } \\
\text { anxiety }\end{array}$ & \\
\hline & $\begin{array}{l}\text { Self-confidence: general self- } \\
\text { efficacy; self-efficacy in } \\
\text { leadership }\end{array}$ & High self-esteem \\
\hline & $\begin{array}{l}\text { Self-confidence: internal locus } \\
\text { of control; independence }\end{array}$ & $\begin{array}{l}\text { Low value on independence; High } \\
\text { expectation for independence; Internal } \\
\text { locus of control }\end{array}$ \\
\hline & Dominance & $\begin{array}{l}\text { Low belief of social criticism; high } \\
\text { belief of alienation }\end{array}$ \\
\hline
\end{tabular}

Some psychosocial traits cannot be directly linked from the leadership education field to the problem behavior prevention field. For instance, ability to turn information into action (Dries $\&$ Pepermans, 2012) does not correlate to any of the traits listed as preventative factors for problem behavior among adolescents. However, it can be inferred that an individual who is able to turn information into action would be able to better apply the information learned in a traditional prevention program (i.e., a leader who is able to turn information into action may be able to apply refusal skills learned in the classroom to real-life situations). Similarly, religiosity, identified as a preventative factor against problem behavior (Jessor, 1987), is not addressed in the leadership education literature. Although leadership education may not make a person more dedicated to religion, it can be inferred that it may increase his or her dedication to a cause or 
organization (i.e.,, a student club, youth group, church). These connections are merely speculative, but logical inference suggests that future research on the connections may improve problem behavior prevention programs.

A review of the literature suggests one risk in applying leadership education to problem behavior prevention. Leadership education has been shown to increase independence (Schneider et al., 2000; Schneider et al., 2002), and high value on independence is a risk factor for problem behavior among adolescents (Jessor, 1987). This suggests that leadership education may actually increase an adolescent's risk for problem behavior. This will be addressed in the recommendations section of the review.

How Could These Links Be Measured? Measurement is critical in the creation of a research-based framework for problem behavior prevention. One of the most difficult challenges faced in this research was inconsistent instruments. While two different instruments may measure essentially the same trait, nuances of specific traits may skew comparative results.

Therefore, I recommend using a consistent evidence-based instrument to measure psychosocial traits. Although it's beyond the scope of this review to choose appropriate measures, the instruments used by Schneider et al. (2000) would, most likely, be effective in measuring psychosocial personality traits in relation to both leadership education and problem behavior prevention. These measures include: the Myer-Briggs Type Indicator, Campbell Interest Skills Survey, and observations of a Leaderless Group Discussion (see Table 1). Schneider et al. (2000) revealed that the Minter Sentence Completion Scale failed in predicting leadership potential, and so I would recommend either replacing or removing the MSCS measure.

\section{Recommendations for Leadership Education Practitioners}

The results of this paper indicate the possibility of a partnership between the fields of leadership education and problem behavior prevention, which could be mutually beneficial to both fields. Adolescent leadership educators often must convey the value of their programs to program participants and participants' parents and caretakers. For students considered at-risk for problem behaviors, leadership education can be a "hard sell" - when teenagers face so many more immediate problems (i.e., drug use, risky sex etc.), parents and teachers may have difficulty seeing the value of leadership education, which is often marketed to high achieving students. However, the framework set forth in this article suggests that leadership education may have a mitigating effect on problem behaviors. Given what we know of problem behaviors among adolescents, it seems likely that leadership education may help at-risk adolescents develop the protective factors that delay the onset or diminish the intensity of problem behaviors. The connection between leadership education and problem behaviors could enhance the value of leadership education for "consumers" (in this case, consumers could be considered participants, parents, schools, youth groups) and may help practitioners access previously difficult to reach audiences, such as low-income, minority, and at-risk youth. If leadership education can promote healthy behaviors among adolescents, this can only add to the list of positive outcomes from leadership education. 
In a similar vein, this connection could help those interested in promoting positive youth development to reach different audiences. Prevention practitioners often face difficulty marketing substance use prevention programs in high-income communities and among academically high achieving students. Leadership education programs may be more marketable, as any student (even those not prone to problem behaviors) can gain life skills from leadership education.

This research also provides one note of caution for leadership educators. Leadership educators should also be careful of the negative implications of leadership education's effect on adolescents. Schnieder et al. (2000, 2002) found that leadership education increases independence, which is not a preventative factor but instead a risk factor for problem behaviors. Therefore, leadership educators should be aware of leadership education's effects on the psychosocial traits of their students, and educators should urge their students to use what they've learned and gained through leadership education responsibly. Further research should inform how responsibility can be enforced in a leadership education program for adolescents.

\section{Recommendations for Other Stakeholders}

Recommendations for Researchers. This review suggests a reasonable basis for a connection between leadership education and problem behavior prevention among adolescents. Several studies have shown that leadership education enhances leadership potential, thereby developing certain psychosocial traits. These same psychosocial traits, when developed, act as preventative factors against problem behaviors among adolescents. This review has attempted to create the blueprints for a bridge between the leadership education and problem behavior prevention fields, and it is now up to future researchers to build the bridge with empirical evidence.

I propose that the following study be performed: a large group of students from varied peer groups and community backgrounds should be block randomly assorted into an experimental group and a control group. Both groups would undergo an observational study to determine their likelihood for problem behavior. In the study, researchers should evaluate psychosocial risk and protective traits, as well as use of and attitudes towards problem behaviors such as drug and alcohol use. The experimental group should receive leadership education through both classroom-based training and structured leadership opportunities designed for students. In accordance with the research reviewed, this leadership education program should ideally both teach students leadership skills and give them a chance to exercise them, as well as provide for coordination with adults in the community. This program would not have to be new; one of the reviewed leadership education programs for adolescents (i.e., 4-H) could be used. The control group should receive an alternative structured and supervised program that is not expected to promote the development of leadership potential (i.e., a chess or physical education class). After the full implementation of the two programs, students should be again surveyed for their involvement in problem behaviors (e.g., drug use, violent behavior) and their attitudes towards different problem behaviors, which together will serve as the dependent variable. The researchers should then compare results to see whether the students in leadership education programs were more, less, or as likely as their peers in the control group to demonstrate prosocial behaviors and attitudes. A study like this would be limited in its ability to find what 
aspects of leadership education are most conducive to risk behavior reduction, but it would provide some empirical data as to whether leadership education, in general, can reduce risk behaviors. If the hypothesis is affirmed, further research can be conducted to determine which aspects of a leadership education program are most important to mitigate risk factors and whether the notion of leadership education as a risk behavior reduction strategy is generalizable to a broader population.

Recommendations for Policy Makers/Prevention Specialists. The research conducted in this review suggests that policy makers and prevention specialists should be careful to consider alternative ways of providing prevention based programming. Over the past 20 years, researchers such as Hawkins et al. (1992) and Jessor (1987) have proven that problem behavior prevention is most effective when considered through psychosocial traits. Too often, policy makers and prevention specialists approach problem behavior prevention strictly in the context of problem behaviors (e.g., programs that tell students to "just say no" to drugs). For instance, drug education programs such as the old version of Drug Abuse Resistance Education (commonly known as D.A.R.E.) focus on the negative effects of drugs, alcohol, violence, and other problem behaviors. However, programs like the old D.A.R.E. program fail to address the underlying psychosocial traits that are influential when an adolescent decides whether or not to engage in problem behaviors. The approach of addressing underlying traits is more effective and is more conducive to the theory of Problem Behavior Prevention (Jessor, 1991) than attempting to address problem behaviors individually and directly.

Therefore, in order to be most efficient, prevention specialists and policy makers should invest their time and resources into "indirect" approaches that address underlying psychosocial traits, such as self-esteem, religiosity, and internal locust of control, instead of instructing students just to say no to drugs.

Recommendations for Concerned Parents. Parents and specifically parents of at-risk youth are often interested in finding ways to reduce the risk that their child will become involved with drugs, alcohol, violence, precocious sex, and other problem behaviors. The research performed in this review would suggest that, like policy makers and prevention specialists, parents should pay careful attention to programs and activities that are likely to increase prosocial psychosocial traits. Specific to this review, concerned parents may want to find ways to involve their adolescent children in leadership education and leadership-building activities and opportunities. By enhancing their children's leadership potential, parents will also enhance the psychosocial personality traits that are proven preventative factors against problem behaviors.

\section{Conclusion}

This review of the problem behavior and leadership education literatures provides promise that leadership education may be an effective strategy to mitigate risk behaviors among adolescents. Previous research conducted on the impact of leadership education programs on participants demonstrate that participants gain or enhance many of the psychosocial traits known to be protective factors for risk behaviors. Therefore, there is promising evidence that leadership education may be an effective strategy of preventing problem behaviors. 
The development of leadership education as an alternative strategy to problem behavior prevention is useful for practitioners in both the leadership education and problem behavior prevention fields. Leadership education practitioners often communicate to parents, schools, and other community groups the compelling evidence that leadership education is valuable for employment, citizenship, and life success. However, too often, leadership educators have trouble accessing youth audiences, as institutions serving youth are burdened by other priorities, including the priority of reducing problem behaviors. By connecting the existing literature, leadership educators can argue that leadership education has the potential to not only grow leadership potential but also reduce problem behaviors among young people.

Problem behavior prevention providers, on the other hand, often face a similar problem. While problem behaviors pose a significant threat to adolescents, some institutions are hesitant to acknowledge the need for prevention programming. Particularly among institutions serving wealthier or higher-performing youth, the need for high-quality prevention programming is often not a high priority. However, these same institutions frequently seek out enrichment programs to grow the potential of their youth clients or students. Prevention program providers can market their service as leadership education, with the comfort of knowing that leadership education is a promising approach to reducing problem behaviors among adolescents.

Of course, further research must be conducted to empirically determine whether leadership education has the potential to prevent problem behaviors among adolescents. Empirical research, such as the study I proposed, certainly has the potential to be resource intensive, both in terms of researchers' time and money. However, leadership education practitioners and problem behavior prevention program providers both face considerable difficulty accessing the adolescent audience, despite the wealth of evidence that both lead to positive outcomes for adolescents, and the discovery of an evidence-based connection between the two fields would facilitate the advancement of both concerns. For this reason, further study in the connection between leadership education and problem behavior prevention is merited. 


\section{References}

Botvin, G. J., Baker, E., Dusenbury, L., Botvin, E. M., \& Diaz, T. (1995). Long-term follow-up results of a randomized drug abuse prevention trial in a white middle-class population. Journal American Medical Association, 273(14), 1106-1112.

Brook, J. S., Brook, D. W., Gordon, A. S., Whiteman, M., \& Cohen, P. (1990). The psychosocial etiology of adolescent drug use: a family interactional approach. Genetic, Social, and General Psychology Monographs.

Catalano, R. F., \& Hawkins, J. D. (1996). A theory of antisocial behavior. Delinquency and Crime: Current Theories (1996), 149.

Donovan, J. E. (2004). Adolescent alcohol initiation: a review of psychosocial risk factors. Journal of Adolescent Health, 35(6), 529-e7.

Dries, N., \& Pepermans, R. (2007). "Real" high-potential careers: An empirical study into the perspectives of organisations and high potentials. Personnel Review, 37(1), 85-108.

Dries, N., \& Pepermans, R. (2012). How to identify leadership potential: Development and testing of a consensus model. Human Resource Management, 51(3), 361-385.

Ellickson, P. L., McCaffrey, D. F., Ghosh-Dastidar, B., \& Longshore, D. L. (2003). New inroads in preventing adolescent drug use: Results from a large-scale trial of Project ALERT in middle schools. American Journal of Public Health, 93(11), 1830-1836.

Flay, B. R. (2002). Positive youth development requires comprehensive health promotion programs. American Journal of Health Behavior, 26(6), 407-424.

Garmezy, N. (1985). Stress-resistant children: The search for protective factors. Recent Research in Developmental Psychopathology, 4, 213-233.

Hawkins, J. D., \& Catalano Jr, R. F. (1992). Communities that care: Action for drug abuse prevention. Jossey-Bass.

Hawkins, J. D., Catalano, R. F., \& Miller, J. Y. (1992). Risk and protective factors for alcohol and other drug problems in adolescence and early adulthood: Implications for substance abuse prevention. Psychological Bulletin, 112(1), 64.

Higham, R., Freathy, R., \& Wegerif, R. (2010). Developing responsible leadership through a 'pedagogy of challenge': An investigation into the impact of leadership education on teenagers. School Leadership and Management, 30(5), 419-434.

Hogan, R., Curphy, G. J., \& Hogan, J. (1994). What we know about leadership: Effectiveness and personality. American Psychologist, 49(6), 493. 
Jessor, R..(1987). Problem-behavior theory, psychosocial development, and adolescent problem drinking. British Journal of Addiction, 82(4), 331-342.

Jessor, R. (1991). Risk behavior in adolescence: A psychosocial framework for understanding and action. Journal of Adolescent Health, 12(8), 597-605.

Jones, K. R. (2009). Influences of youth leadership within a community-based context. Journal of Leadership Education, 7(3), 246-264.

Katz, E. C., Fromme, K., \& D'Amico, E. J. (2000). Effects of outcome expectancies and personality on young adults' illicit drug use, heavy drinking, and risky sexual behavior. Cognitive Therapy and Research, 24(1), 1-22.

Marcketti, S. B., \& Kadolph, S. J. (2010). Empowering student leadership beliefs: An exploratory study. International Journal of Teaching and Learning in Higher Education, 22(2), 131-139.

McCormick, M. J., Tanguma, J., \& López-Forment, A. S. (2002). Extending self-efficacy theory to leadership: A review and empirical test. Journal of Leadership Education, 1(2), 34-49.

Murphy, S. E. (2011). Providing a foundation of leadership development. In Murphy, S. E., \& Reichard, R. J. (Eds.), Early Development and Leadership: Building the Next Generation of Leaders (pp. 3-37). New York: Routledge.

Murphy, S. E., \& Reichard, R. (Eds.). (2012). Early development and leadership: Building the next generation of leaders. Routledge.

Petersen, A. C., \& Epstein, J. L. (1991). Development and education across adolescence: An introduction. American Journal of Education, 373-378.

Popper, M., \& Mayseless, O. (2007). The building blocks of leader development: A psychological conceptual framework. Leadership \& Organization Development Journal, 28(7), 664-684.

Reichard, R. J., Riggio, R. E., Guerin, D. W., Oliver, P. H., Gottfried, A. W., \& Gottfried, A. E. (2011). A longitudinal analysis of relationships between adolescent personality and intelligence with adult leader emergence and transformational leadership. The Leadership Quarterly, 22(3), 471-481.

Rutherford, T. A., Townsend, C. D., Briers, G. E., Cummins, R., \& Conrad, C. R. (2002). Leadership self-perceptions of WLC participants. Journal of Agricultural Education, $43(2), 22-33$.

Rutter, M. (1985). Resilience in the face of adversity: Protective factors and resistance to psychiatric disorder. The British Journal of Psychiatry, 147(6), 598-611. 
Schneider B., Ehrhart, K. H., \& Ehrhart, M. G. (2002). Understanding high school student leaders: II. Peer nominations of leaders and their correlates. The Leadership Quarterly, 13(3), 275-299.

Schneider B., Paul, M. C., White, S. S., \& Holcombe, K. M. (2000). Understanding high school student leaders, I: Predicting teacher ratings of leader behavior. The Leadership Quarterly, 10(4), 609-636.

Spreitzer, G. M., McCall, M. W., \& Mahoney, J. D. (1997). Early identification of international executive potential. Journal of Applied Psychology, 82(1), 6.

Stewart, B. R. (1985). Member, Officer, and Advisor Perceptions of FFA Organizational Goals and Activities. Journal of the American Association of Teacher Educators in Agriculture, 26(2), 47-55.

Swigert, T., \& Boyd, B. L. (2010). The impact of Boys \& Girls Club/Keystone Club participation on alumni. Volume 9, Number 1-Winter 2010, 69.

Taylor, E. L., \& Rosselli, H. (1997). The effect of a single gender leadership program on young women.

Tebes, J. K., Feinn, R., Vanderploeg, J. J., Chinman, M. J., Shepard, J., Brabham, T., ... \& Connell, C. (2007). Impact of a positive youth development program in urban afterschool settings on the prevention of adolescent substance use. Journal of Adolescent Health, 41(3), 239-247.

Terzian, M. A., Andrews, K. M., \& Moore, K. A. (2011). Preventing multiple risky behaviors among adolescents: Seven strategies. Child Trends, 2011-24.

\section{Author Biography}

Theodore L. Caputi is a Joseph Wharton Scholar at the Wharton School at the University of Pennsylvania and a Junior Fellow at the University of Florida's Drug Policy Institute. He researches substance abuse and addiction, with a focus on adolescent substance use prevention, and coordinates a leadership non-profit functioning in 13 Philadelphia public schools. 